\title{
HISTORY OF THE SOCIAL SCIENCES
}

RÉSUME. - Comme prolégomène à toute historiographie future des sciences sociales, l'auteur soutient que le sujet ne saurait être traité comme la somme des développements parallèles dans des disciplines séparées, dont les états antérieurs ne sont considérés que relativement à leur état actuel. Les chercheurs seraient mieux inspirés de concevoir leur sujet comme un ensemble de questions sur le rôle historique de la systématisation et de l'institutionnalisation des connaissances sur l'homme en société. Des travaux portant sur des aspects plus particuliers de cette problématique globale seraient sans doute plus prometteurs que des histoires internes à chaque discipline destinées aux spécialistes de l'histoire actuelle.

The creation of the Sociéte française pour l'histoire des sciences de l'homme is a sign among many of widespread recognition that the history of the human and social sciences is a discipline whose time has come. Or should have come. The choice of the preposition "pour" rather than "de " does consciously signify that people ought to be doing the history of the social sciences, not that many of them are. There are, certainly, a few pioneers to be glimpsed moving about out there beyond the frontier, charting paths, dispelling legends, and clearing the ground. Such is the pre-disciplinary stage of any learned subject. A moment then comes, and this may be one such, when institutionalization cradles the infant body of knowledge. The birth may, on the other hand, be premature or even abortive.

For the test of the viability of any set of beliefs, ideas, or intellectual constructions is precisely its capacity to form durable institutions. The merit of the pioneers is just that they are amateurs, in the literal sense. Their enthusiasm is a propellent, but an impulse cannot develop momentum unless there is a body to which it may be imparted. So it was in the development of the history of science when the History of Science Society was founded in 1924. So it was in the History of

Revue de synthèse: IV S. Nos 3-4, juil.-déc. 1988. 
Technology when its Society was founded in 1958. So it was with many a new subject in the 19th century, among them the disciplines of which we now propose to study the history.

Does it follow that they are best studied discipline by discipline? Such was the deliberate will of the officials of the CNRS in the very interesting "Colloque de définition sur l'histoire des sciences sociales et humaines" sponsored by. the Centre national de la recherche scientifique, in which I had the honor to participate on 14 and 15 April 1986. The working papers consisted of a series of reports on topics such as "Histoire de la sociologie en France", "Histoire de la démographie ", "Histoire de la statistique ", " Histoire de l'ethnologie en France ", "Histoire de l'anthropologie ", and so on to the number of some twenty odd. The quantity and intellectual quality of those papers were impressive testimony to the intensity of historical interests, I might say historical introspection, within the several disciplines and subdisciplines. Nevertheless, the approach aroused uneasiness in the case of the two foreigners present, Stefan Collini of the University of Sussex and myself. Without any prior consultation, without indeed having met each other before or since, we found we had practically identical things to say, he in the form of a written paper, I in an impromptu comment from the chair.

In sum it was our sense that this strategy would never lead on to a history of the social and human sciences, but at best to a set of chronicles of the past of each discipline recounted according to the lights of its current practitioners. Such an approach might possibly serve the discipline in a methodological way by providing examples of the handling of data and the formation of theory, in a professional way by cementing a sense of community among disciples and practitioners, in an edifying way by exhibiting the achievements of great men and women in some heroic past, and perhaps in other ways peculiar to each discipline. The field, or rather furrows, would necessarily be cultivated, not as a sub-discipline of the historical profession, but by members of each of the several disciplines, anthropologists, economists, sociologists, political scientists, etc., writing histories of their subjects for their own benefit. Now then, the development of the social sciences has not in fact recapitulated the development of the natural sciences, and there is no a priori reason that their respective historiographies should do so. Nevertheless, it has to be said that in this respect, the example of the history of the natural sciences may be taken as a warning.

Before becoming a field of historical inquiry at a time within the memory of many now practising it, it was written either by philosophers or by scientists - retired scientists, disappointed scientists, or scientists 
astride a hobby horse. Whatever else can be said about the results, they do not constitute a body of serious historical literature. Only when historians (usually but not always with prior training in science) took it up did it become that, and if I am not mistaken - except for the papers on history and sociology - Collini's was the only paper contributed to the CNRS colloquium by a professional historian.

There are cultural reasons that led French scholarship to take the formal initiative of that colloquium and institutional reasons for its having been conceived as it was. Historical sensibility is a dominant trait in French culture. Not so in the United States, where it is recessive at best. I cannot imagine a large group of active scientists or social scientists in the United States participating in a conference on the desiderata of a history of science, even conceived as histories of their separate sciences. In France, by contrast, history is everybody's business. A no less spirited occasion than the CNRS colloquium was a symposium at the Universite de Nantes in October 1980 on teaching the history of science to scientists. Organizationally, the conception was identical. The reports, proceeding science by science, were didactic and methodological in spirit and not really historical. For what is everybody's business in particular is nobody's business in general. It is significant that a separate conference at a later date addressed the teaching of the history of science to historians. In France, the institutional obstacle, in a word, to a collective historiography, whether of science or of social science, is the extreme compartmentalization of the university structure faculty by faculty and discipline by discipline. As Jacques Roger pointed out in a conversation about this subject, you say "Histoire des Sciences" and we say "History of Science".

That institutional pattern is not going to change overnight, or perhaps at all, and there are undoubtedly reasons more compelling than the subject of this essay that it should not. Still, there ought to be ways to adapt the development of a historiography of the social sciences to the given structures. Again, the experience of the historiography of science may be suggestive. What are the sorts of questions that have produced its literature? All of them, I think, are subsidiary to the realization, borne in on historical sensibility by the whole weight of the times we have been living in since the last war, that science is, not just knowledge of nature, but a major force, some would say the major force in modern times, affecting the course of all history, as an instrument of power and of much else besides.

Some would go so far as to say, and I would agree, that in respect of the history of western civilization, science is one of the two differentiating factors that distinguish our culture from the others that 
have known the world. From one of those factors it derived Christianity. The other it produced - modern science. It is, moreover, to technical, not cultural or spiritual or any other, superiority that Europe and the United States came to dominate the world until yesterday. The process began overtly with the voyages of discovery in the 15 th century. They were animated by that geographical and even geopolitical dynamism that eventually carried spacecraft to the moon, and what differentiated them from the random travels of antiquity and of other civilizations, which produced only adventure, legend, or commerce, is that they were always involved with - I do not say motivated by - the problem of how the world is made, in a word with knowledge of nature.

The great questions, then, are why did Europe and Europe alone produce modern science and in what ways has the development of science entered into, shaped and been shaped by, the other aspects of the western historical experience - political, economic, social, moral, and artistic? A further class of questions arises in very recent times - what are the effects on other cultures, and indeed on ours, of the incorporation of the scientific enterprise into their own fabrics? For it is a feature of contemporary world history that science - in all this I include technology - is the one aspect of western practise that leaders of other societies want. They do not want our beliefs and churches, our political systems, our social structures, our economic practises, our art and literature. Beginning with the Japanese, they have wanted science, in order to free themselves from constraints of many sorts, including us, and they can acquire and operate it with more or less success, the degree of which is itself an interesting object of historical inquiry.

Questions of other sorts about science in the past may appeal to philosophers, sociologists, or scientists themselves, but those are the global problems that appeal to the historical imagination, consciously or unconsciously. The investigations that win attention are calculated to illuminate them directly or indirectly, in whole or in part. There are no doubt many ways in which such investigations may be classified. I find it useful to think of them under two broad headings, each with two divisions of which one is concerned with the practise of science and the other with its relations to the larger society.

The first broad heading comprises studies of the genesis of science. Why should it be done at all and to what do we attribute its apparent success? Notable examples analyzing the role of the internal dynamics of scientific practise are the work of Thomas S. Kuhn and the more recent writings of the school that calls itself social constructionist. As for the role of the external social environment in the making of science, any serious Marxist account would serve as an example of studies of 
this set of problems. So, also, does the literature exhibiting the effect of the last world war on the science of physics. As a third instance, I shall summarize an argument, not original with me, that I have never elaborated in print but only in teaching. It holds that the culture of the Renaissance in Italy was the matrix wherein ancient and scholastic learning and technique were converted into modern science and engineering. We there encounter the first manifestation of the instinct that formed modern science : namely, that knowledge finds its purpose in action and action its reason in knowledge; that if a problem can be solved, it should be solved; that if something can be done, it should be done.

Studies that come under the second broad heading deal with what may be called great junctures, and they too may be divided into those concerned with science proper and those concerned with its relation to historical circumstances. The concept of revolutions is prominent in both. In the former case, the most densely populated loci of research have been the Scientific Revolution of the 17th century, and the chemical, the Darwinian, and the quantum mechanical revolutions. In the latter, the place of science in the French, the Russian, and the Industrial revolutions has invited investigation, as have the relations of science to broader historical constructs such as the Middle Ages, Puritanism, the Enlightenment, the social structure, nationalism and cultural values, notably in the German, American and Russian cases, the role of patronage, of professionalism, of discipline formation, and so on. In general, historical studies of individual scientists, of national science, of particular sciences, of institutions, can, I think, be assimilated to one or several of these broad categories.

What makes them historical is that they are concerned with explaining, not just pieces of past science, but the development of science in the past. The historian has to know what the pieces were, but they are not his problem, not for their own sake. His problem is how and why one piece or set of pieces led to another in time and circumstance. $\mathrm{He}$ is the evolutionary student of past science, not its taxonomist. The sciences are his species, society is their environment. The center of his interest is in the historical process, and how science fits into it.

In this respect the history of science is different, qualitatively at least, from the history of art, philosophy, or literature. In universities those subjects characteristically are studied and taught within the departments concerned with the parent humanistic disciplines. Why should that be so in the humanities, and somehow seem right? I do not fully know, but there may be two sorts of reasons, not merely accidental. For one thing, the creations of the past are a part of the living corpus of art, 
literature and philosophy in a way that is not true of science. For another thing, and of this I am less confident, there may be a sense in which the humanities are to be apprehended rather as products than shapers of history, as timeless in their claims if not their reference. Their interest for the general historian is as windows into the past, rather than as forces making for change and for the future.

What, then, of the social sciences? If the distinctions just set out have any merit, they point to a dichotomy between the historical roles of cultural artefacts and systematic knowledge, and surely the social sciences belong with the sciences in the latter category. Their interest, too, is as terms in the "Savoir-Pouvoir" equation, not as germs of their present selves.

That something of the sort may long have been obscurely felt will be suggested by what we think we know of them even in the present state of their historiography. With very few exceptions, that has not developed beyond the stage of descriptive intellectual history - accounts of the ideas of the great men in more or less analytical precis and paraphrase. Even at that level, the ones who figure in historical awareness are those whose ideas appear to have formed or styled events rather than others whose methodologies might, perhaps, be equally edifying or more so. That is why every educated person knows quite a lot about Karl Marx and very little, say, about Proudhon, whatever the merits of the latter in the abstract.

The same is true of the classical economists and the utilitarian political scientists. It is no reflection on the cogency of their writings to say that it is rather their relation to industrial capitalism that explains the historian's familiarity with their doctrines. The point may be developed by contrasting their collective reputation with that of their contemporaries in France, the would-be social scientists of the Directory and Consulate known as Idéologues.

Their very names are unknown to any but specialists in the period. Why should their attempt to found the social sciences as formal disciplines have plunged them into such obscurity? The answer is certainly not that they wrote bad books. Let us try a thought experiment. Let us endow Micromégas, or Condillac's statue, with knowledge of the content of the political theory, the economics, and the sociology published in the last ten years, carefully expurgated of the few historical allusions it may contain. Let us then seat him before two piles of books, the one consisting of the writings of the classical economists and the utilitarians, with Francis Place, Godwin, and Cobbett thrown in, the other stack containing the works of the Idéologues together with Dupont de Nemours and Say. I do not believe that our reader would judge 
that the disciplines he has just learned evolved out of the former and not out of the latter. In Destutt de Tracy's Éléments d'idéologie may be found a behaviorist political theory, a general grammar, a social psychology, and a doctrine of political economy denounced by Marx. In Cabanis's Rapports du physique et du moral de l'homme may be found a treatise of psycho-somatic and social medicines. In Degérando's Des signes may be found the germ of semiotics, and very expressly. In Volney's Leçons de l'histoire may be found nothing less than a charter for comparative history.

François Picavet, Georges Gusdorf, and Sergio Moravia, to name only the outstanding scholars, have successively and respectively written voluminous tomes expounding the works of the idéologues. Why have they failed, for I fear they have, to impress the importance of their subjects on historical sensibility? The reason in my own view, which I hope to develop elsewhere, may be that the systematic writings of the idéologues were marginal to the actual events of their times. However prescient they appear in the eyes of later social scientists, their contemporary importance was in their institutional and political activities, with respect to the Institut de France and to the educational system, with respect to the constitutions of the Directory and Consulate, with respect to the coup d'état of 18 Brumaire. If they were studied relative to those activities, rather than to the later findings of the social sciences, they might come alive. When it is a question of the growth of serious knowledge of contemporary society, the place to look is not in their writings, but in the acts of a newly positive, indeed a positivist, administration, for example in Chaptal's conduct of the Ministry of the Interior. We might then begin to resolve one of the great paradoxes of the history of the French Revolution: in the country in which intellectuals have been the most systematically involved in political and social discourse throughout modern history, their representatives appear to dim to insignificance in the quarter century that marks the zenith of French political history.

Those suggestions are ventured in a more tentative spirit than may appear. They undoubtedly require modification and are meant less as assertions than as illustrations of the main proposition of this essay. It is that in order to command attention, the history of the social sciences will need to exhibit the ways in which organized knowledge of society has itself entered as a factor into the historical process.

Charles C. GILLISPIE, Princeton University December, 1987. 